Check for updates

Cite this: Chem. Commun., 2020, 56,12813

Received 29th June 2020,

Accepted 15th September 2020

DOI: $10.1039 / \mathrm{d} 0 \mathrm{cc} 04489 \mathrm{j}$

rsc.li/chemcomm

\section{Dibenzocycloheptatriene as end-group of Thiele and tetrabenzo-Chichibabin hydrocarbons $\dagger$}

\author{
Vicente G. Jiménez, (D) $\ddagger^{\mathrm{a}}$ Paula Mayorga-Burrezo, (D) $\ddagger^{\mathrm{b}}$ Victor Blanco, (D) a \\ Vega Lloveras, (D) ${ }^{b}$ Carlos J. Gómez-García, (D) ${ }^{c}$ Tomáš Šolomek, (DD \\ Juan M. Cuerva, (D) Jaume Veciana (iD ${ }^{\text {b }}$ and Araceli G. Campaña (iD *a $^{a}$
}

Thiele (Th) and tetrabenzo-Chichibabin (TBC) derivatives with terminal dibenzocycloheptatriene (DBHept) units were prepared. A clear correlation between their electronic and molecular structures was stablished. Insights into their closed- or open-shell ground states were gained, where particular contribution of the heptagonal carbocycles as end-groups was proved. Remarkably, a thermally accessible triplet diradical configuration was confirmed for the DBHept-TBC compound.

Electronic structure of polycyclic aromatic hydrocarbons ${ }^{1}$ (PAHs) with small HOMO-LUMO gap appears as halfway between closed(CS) and open-shell (OS) with two possible spin configurations: a singlet (SOS) and a triplet (TOS). As a result, a number of intriguing properties may arise in these so-called diradicals, ${ }^{2}$ such as twophoton absorption enhancement, ${ }^{3}$ singlet fission, ${ }^{2,4}$ interesting chiroptical, ${ }^{5}$ or amphoteric redox ${ }^{6}$ behaviour. In the case when the frontier MOs are disjoint (i.e. have no atoms in common), a small singlet-triplet energy gap and thermally accessible magnetism may arise. Several $\pi$-extended diradical PAHs based on ortho- or para-quinodimethanes (o-/p-QDM), ${ }^{7}$ such as indenofluorenes, zethrenes, teranthrenes and others, have been reported. ${ }^{8}$ Among them, Thiele ${ }^{9}$ and Chichibabin ${ }^{10}$ PAHs, the first reported diradicals, are of particular interest (Chart 1A). Organic chemists have devoted great effort to analyse their peculiar $\mathrm{CS} / \mathrm{OS}$ resonance while battling their high reactivity. ${ }^{11}$ The gain in steric hindrance between the (diphenyl)-methyl

\footnotetext{
${ }^{a}$ Department of Organic Chemistry, Unidad de Excelencia de Quimica aplicada a Biomedicina y Medio Ambiente, University of Granada (UGR), C. U. Fuentenueva, Granada 18071, Spain. E-mail: araceligc@ugr.es

${ }^{b}$ Department of Molecular Nanoscience and Organic Materials, Institut de Ciència de Materials de Barcelona (ICMAB)/CIBER-BBN, Campus Universitari de Bellaterra, Cerdanyola, Barcelona, E-08193, Spain. E-mail: vecianaj@icmab.es ${ }^{c}$ Department of Inorganic Chemistry and Instituto de Ciencia Molecular, Universidad de Valencia, Paterna 46980, Spain

${ }^{d}$ Department of Chemistry, University of Basel, St. Johanns-Ring 19, Basel 4056, Switzerland

$\dagger$ Electronic supplementary information (ESI) available: Synthetic procedures, further details and additional figures. CCDC 2012097 and 2012098. For ESI and crystallographic data in CIF or other electronic format see DOI: 10.1039/d0cc04489j

\# Both authors contributed as first authors.
}

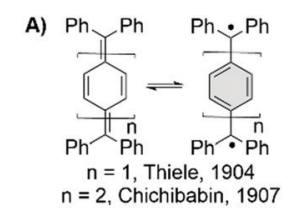

C) Fluorene as end-groups
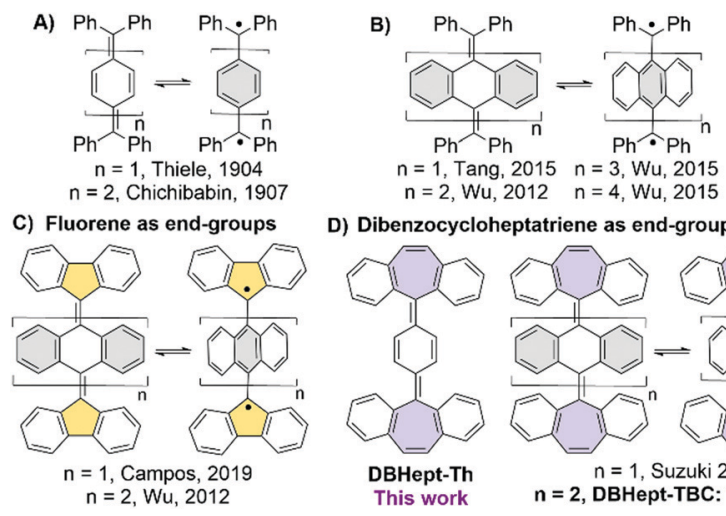

D) Dibenzocycloheptatriene as end-groups
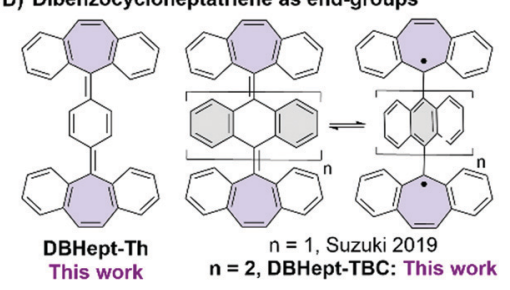

Chart 1 CS (left) and OS (right) forms of previously reported: (A) Thiele (Th) and Chichibabin hydrocarbons, (B) tetrabenzo-Chichibabin (TBC) hydrocarbon, (C) TBC-derivatives with terminal fluorene groups. (D) Previous and new Th and TBC-derivatives incorporating dibenzocycloheptatriene (DBHept) as end-groups.

end-groups and the central aromatic rings extended to anthracenes $^{12,13}$ (Chart 1B) twists the structure and diminishes the exchange between the two spins. This enhances the SOS character and lowers the singlet-triplet gap.

By increasing the length of the spacers $(n=2 \rightarrow 4$, Chart 1B), $\mathrm{Wu}$ et al. observed a slow conversion of the OS orthogonal structure to the quinoidal CS singlet state with contorted butterfly-like geometry $(n=1) \cdot{ }^{13}$ In the extreme case $(n=3,4)$, the derivatives behaved like uncoupled radicals in the solid-state EPR experiments. In recent years, the effect of the end-groups has been explored ${ }^{14}$ including carbenes ${ }^{14 c-h}$ or non-hexagonal carbocycles. Using fluorenyl end-group, Wu et al. stabilized ${ }^{13 a}$ the orthogonal geometry $(n=2$, Chart 1C) with the OS electronic configuration and Campos et al. showed a thermal interconversion of stable CS/OS forms ( $n=1$, Chart 1C). ${ }^{15}$ Only the CS form with no hints of a radical behaviour was recently reported by Suzuki et al. when a heptagonal (i.e. dibenzocycloheptatriene, DBHept) end-group $(n=1$, Chart 1D) was employed. ${ }^{16}$ The same observation was done by some of us with cumulenes as the conjugated bridges between two DBHept groups. ${ }^{17}$ 
Only few other examples of radicals stabilized using heptagonal rings can be found, ${ }^{18}$ mostly as a combination of five- and sevenmembered rings. ${ }^{18 c, d, f}$ To further investigate the effect of heptagonal end-groups on quinoidal PAHs, herein, we report the synthesis and properties of new DBHept derivatives (Chart 1D), Thiele DBHept-Th and tetrabenzo-Chichibabin DBHept-TBC.

Firstly, DBHept-Th was prepared following the synthetic strategy described in Scheme 1A. Double lithium-halogen exchange in 1,4-dibromobenzene, and subsequent nucleophilic addition to dibenzosuberenone afforded diol 1. DBHept-Th was then achieved by reduction of 1 with $\mathrm{SnCl}_{2}$ in $\mathrm{CH}_{2} \mathrm{Cl}_{2}$. Noteworthy, DBHept-Th resulted to be bench stable at air and light. The CS nature of DBHept-Th was fully characterized by means of NMR and IR spectroscopies as well as high-resolution mass spectrometry (HRMS, ESI-TOF) (see ESI $\dagger$ ). Single crystals of DBHept-Th for $\mathrm{X}$-ray analysis were also grown by slow evaporation of hexane/ $\mathrm{CH}_{2} \mathrm{Cl}_{2}$ solutions, showing the saddle curvature of the end-groups caused by the heptagonal carbocycles and the typical $\mathrm{C}-\mathrm{C}$ bond distances alternation of the $p$-QDM core (ESI, $\dagger$ Fig. S8). UV-Vis spectrum of DBHept-Th in $\mathrm{CH}_{2} \mathrm{Cl}_{2}$ showed the lowest energetic absorption band between 340 and $430 \mathrm{~nm}\left(\lambda_{\max }=386 \mathrm{~nm}\right)$, in good agreement with a CS ground state (ESI, $\dagger$ Fig. S9). Remarkably, this CS form remained stable after heating up to $373 \mathrm{~K}$ in $\mathrm{C}_{2} \mathrm{D}_{2} \mathrm{Cl}_{4}$, as observed by VT-NMR (ESI, $\dagger$ Fig. S4). As expected, no ESR response was obtained for DBHept-Th in $o$-DCB even after heating up to $360 \mathrm{~K}$ (ESI, $\dagger$ Fig. S11). In contrast to DBHept-Th, previous reports on the isolation of Th analogues with terminal fluorenyl units showed to be very difficult. ${ }^{19}$ Consequently, these results show the positive role of heptagonal carbocycles as end-groups for the stabilization of $p$-QDM units in Thiele PAHs and DBHept-Th represents the first example of a Thiele PAH analogue incorporating heptagonal carbocycles as end-groups.

Having studied the behaviour of DBHept-Th, we wondered what the influence of heptagonal rings as end-groups in a Chichibabin-hydrocarbon would be. However, due to its known high reactivity, we chose its higher kinetically stable analogue, tetrabenzo-Chichibabin hydrocarbon (TBC) with 9,9'-bianthracene central core, presented by Wu and co-workers. ${ }^{13 a}$ The synthesis of

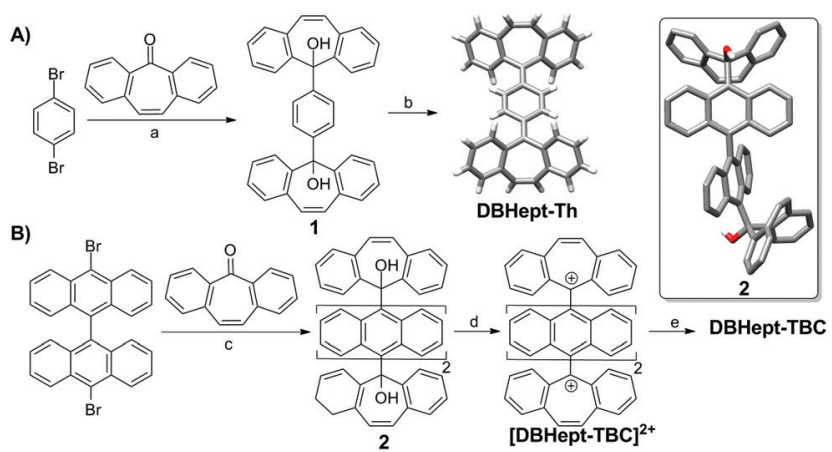

Scheme 1 (A) Synthesis of DBHept-Th. (a) $n B u L i, T H F,-78{ }^{\circ} \mathrm{C}, 1 \mathrm{~h}$; then dibenzosuberenone, $\mathrm{THF}-78{ }^{\circ} \mathrm{C}$ to r.t., $16 \mathrm{~h}, 25 \%$. (b) $\mathrm{SnCl}_{2}, \mathrm{CH}_{2} \mathrm{Cl}_{2}$, r.t., $24 \mathrm{~h}, 62 \%$. (B) Synthesis of DBHept-TBC. (c) $n B$ BuLi, THF, $-78{ }^{\circ} \mathrm{C}, 1 \mathrm{~h}$; then dibenzosuberenone, $\mathrm{THF}-78{ }^{\circ} \mathrm{C}$ to r.t., $16 \mathrm{~h}, 86 \%$. (d) $\mathrm{TFA}-\mathrm{d}, \mathrm{CD}_{2} \mathrm{Cl}_{2}$, 1 min, r.t. (e) Ferrocene $(\mathrm{Fc}), \mathrm{CD}_{2} \mathrm{Cl}_{2}, 1 \mathrm{~min}$, r.t. Single crystal $\mathrm{X}$-ray structures of DBHept-Th and $\mathbf{2}$ (inset) are shown.
DBHept-TBC (Scheme 1B) started from 10,10'-dibromo-9,9'bianthracene, by a double lithium-halogen exchange and nucleophilic addition to dibenzosuberenone giving diol 2 . The resolved X-ray crystal structure of 2 showed the 9,9'-bianthracene core in an orthogonal geometry and the saddle shape of the dibenzosuberenol moiety (ESI, $\uparrow$ Fig. S8). DBHept-TBC was generated by a stepwise protocol and monitored by ${ }^{1} \mathrm{H}-\mathrm{NMR}$.

First, titration of 2 with trifluoroacetic acid- $d$ (TFA- $d$ ) in $\mathrm{CD}_{2} \mathrm{Cl}_{2}$ afforded a red solution of $[\mathrm{DBHept}-\mathrm{TBC}]^{2+}$ with two $\mathrm{CF}_{3} \mathrm{COO}^{-}$as counterions. ${ }^{1} \mathrm{H}-\mathrm{NMR}$ confirmed the generation of the dication with a pronounced downfield shift of the proton resonances in the dibenzotropylium moieties, as expected from the deshielded environment (Fig. 1A, bottom to middle). HRMS also confirmed the formation of the [DBHept-TBC] ${ }^{2+}$ (ESI, $\dagger$ Fig. S50). According to the DFT calculations at B3LYP/6-31G(d,p) in $\mathrm{CH}_{2} \mathrm{Cl}_{2}$ level,

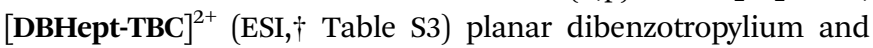
anthracene units are orthogonal in good agreement with similar reported dicationic species. ${ }^{20}$

Electrochemical properties (ESI, $\dagger$ Section S8) of [DBHept-TBC] $]^{2+}$ were then investigated by cyclic and square wave voltammetry, where two reversible reductions $\left(E_{\mathrm{red}}^{1 / 2}=-0.25 \mathrm{~V}\right.$ and $-1.02 \mathrm{~V} v s$. $\left.\mathrm{Fc} / \mathrm{Fc}^{+}\right)$and two quasi-reversible oxidations processes $\left(E_{\mathrm{ox}}^{1 / 2}=1.18 \mathrm{~V}\right.$ and $\left.1.44 \mathrm{~V} v s . \mathrm{Fc} / \mathrm{Fc}^{+}\right)^{+}$, due to the oxidation of the two anthracene moieties, were observed. Consequently, DBHept-TBC could easily be obtained from [DBHept-TBC] $]^{2+}$ by addition of an adequate reducing agent, such as excess of ferrocene (Fc). Thus, chemical reduction of [DBHept-TBC] $]^{2+}$ in $\mathrm{CD}_{2} \mathrm{Cl}_{2}$, by adding an excess of Fc, was followed by ${ }^{1} \mathrm{H}-\mathrm{NMR}$ (Fig. 1A, top) showing the disappearance of the protons at the terminal DBHept units (central, red signals) and suggesting the presence of paramagnetic species. The signals associated with the protons in the 9,9'-bianthracene core of [DBHept-TBC] $]^{2+}$ (central, blue signals) were remarkably broad (top). In this regard, similar partial broadening has been reported for twisted OS diradicals too. ${ }^{21}$

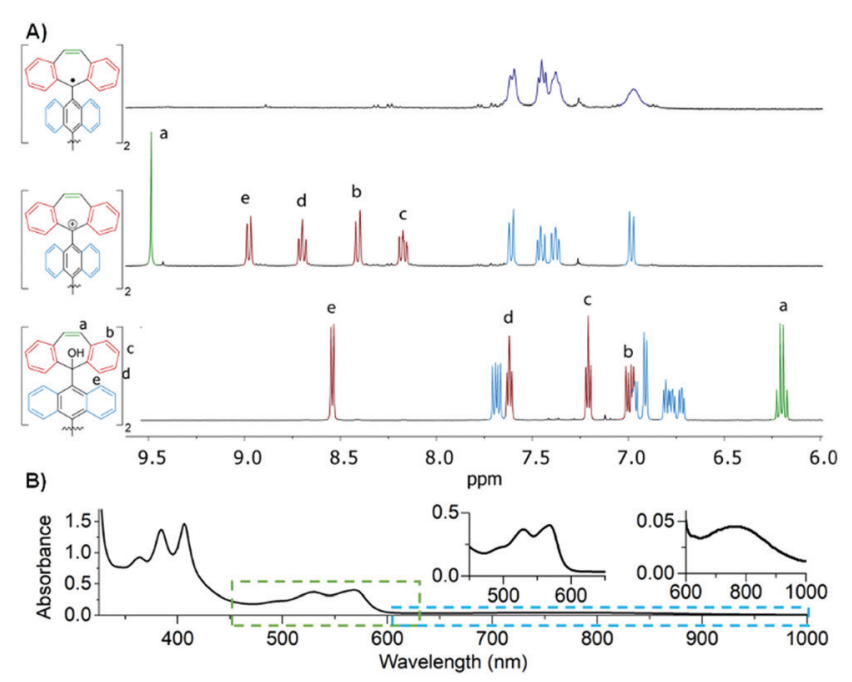

Fig. 1 (A) Partial ${ }^{1} \mathrm{H}$ NMR (400 MHz, $\mathrm{CD}_{2} \mathrm{Cl}_{2}, 298 \mathrm{~K}, 3.2 \mathrm{mM}$ ) of 2 (bottom), upon addition of TFA- $d$ to generate [DBHept-TBC] ${ }^{2+}$ (middle) and subsequent addition of FC to DBHept-TBC (top). (B) UV-Vis-NIR absorption spectrum of DBHept-TBC $\left(\mathrm{CD}_{2} \mathrm{Cl}_{2}, 0.1 \mathrm{Mm}\right.$, r.t.). 
The formation of DBHept-TBC was further confirmed by HRMS (ESI, $\dagger$ Fig. S52).

VT- ${ }^{1} \mathrm{H}-\mathrm{NMR}$ experiments (ESI, $\dagger$ Section S3) were run for the generated DBHept-TBC. High- $T$ experiments in $\mathrm{C}_{2} \mathrm{D}_{2} \mathrm{Cl}_{4}$ showed a marked line broadening upon heating up to $373 \mathrm{~K}$ while low- $T$ experiments in $\mathrm{CD}_{2} \mathrm{Cl}_{2}$ (down to $237 \mathrm{~K}$ ) afforded again the signals of $[\text { DBHept-TBC }]^{2+}$. Since returning to r.t. favoured again the disappearance/broadening of the signals, a subtle equilibrium between DBHept-TBC/[DBHept-TBC $]^{2+}$ in the presence of $\mathrm{Fc} / \mathrm{Fc}^{+}$at low temperatures was considered. Accordingly, the chemical reversibility of DBHept-TBC/[DBHept-TBC $]^{2+}$ was also proved by addition of tris(4-bromophenyl)ammoniumyl hexachloroantimonate as oxidant to a $\mathrm{CD}_{2} \mathrm{Cl}_{2}$ DBHept-TBC solution, as the $[\text { DBHept-TBC }]^{2+}$ NMR signals were again restored (ESI, $\uparrow$ Fig. S3).

Electron spin resonance (ESR) measurements (ESI, $\dagger$ Section S6) were conducted in $o$-dichlorobenzene, aiming at assessing the electronic structure of DBHept-TBC. A spectrum with five groups of partially overlapped lines $(g=2.00263)$ was recorded at $400 \mathrm{~K}$ (Fig. 2a). Remarkably, this signal was only accessible at high temperature. On the contrary, an ESR-silent response was obtained at r.t., and importantly, VT-ESR experiments showed the reversibility of the process. No half-field signal, typical of triplets, was observed since frozen solutions are needed to this purpose. The associated isotropic hyperfine coupling constants with five different pairs of $\mathrm{H}$ nuclei were determined by simulation from the optimized structure of the triplet diradical state (DFT//UCAMB3LYP/6-31G(d,p) level of theory, see $a_{\mathrm{H}}$ values in Fig. 2c). The obtained data are in good agreement with previous results reported by Kubo et al., for anthracene-attached tricyclic monoradicals having one seven-membered ring. ${ }^{18 e}$

Despite all our efforts, we could not grow suitable single crystals of DBHept-TBC for X-ray diffraction. Instead, we isolated a deep red amorphous solid by precipitation of DBHept-TBC solution with $\mathrm{Et}_{2} \mathrm{O}$. The isolated solid displayed the same behavior as the samples generated in situ in solution. Thus, by re-dissolving this solid in $\mathrm{CD}_{2} \mathrm{Cl}_{2}$ or $o$-DCB we obtained the same NMR, UV-Vis or ESR spectra, respectively. The UV-Vis spectrum showed the typical vibronic progression of anthracene (350-400 nm, Fig. 1B) and a long absorption tail in the near-IR region typical for similar OS diradicals (Chart $1 \mathrm{C}, n=2) .{ }^{13 a}$ Note that the same UV-Vis spectrum was obtained by in situ reduction of either [DBHept-TBC] $]^{2+}$ with Fc or diol 2 with $\mathrm{SnCl}_{2}$, (ESI, $\dagger$ Fig. S10).
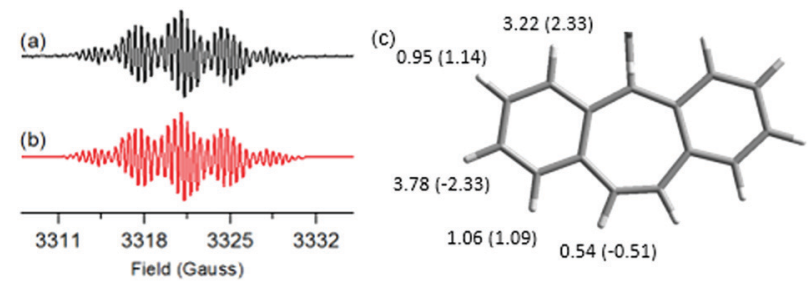

Fig. 2 (a) Experimental (black, $10^{-4} \mathrm{M}$ in $0-\mathrm{DCB}, 400 \mathrm{~K}, g=2.00263$ ) and (b) simulated (red) ESR spectra of DBHept-TBC. (c) Experimentally determined $a_{H}$ values by simulation (in G) for DBHept-TBC. In parentheses, the calculated values at the DFT//UCAM-B3LYP/6-31G(d,p) level of theory, over a fraction of the optimized structure for the triplet diradical state.
Magnetic susceptibility data (ESI, $\uparrow$ Section S9) of this solid also provided insight into the electronic structure of DBHept-TBC. The temperature dependence of $\chi_{\mathrm{m}} T$ (2 to $350 \mathrm{~K}$ ) shows that the magnetic moment steadily increases with temperature without achieving a constant value at high temperatures and attaining a value of $0.4 \mathrm{~cm}^{3} \mathrm{~K} \mathrm{~mol}^{-1}$ at $350 \mathrm{~K}$, which is lower than the expected one of $0.75 \mathrm{~cm}^{3} \mathrm{~K} \mathrm{~mol}^{-1}$ for two independent $S=1 / 2$ spins. This indicates that there is an antiferromagnetic interaction in DBHept-TBC and it has a singlet $(S=0)$ ground state with the first triplet $(S=1)$ excited state accessible thermally at high temperature. The obtained data can be fitted with the Bleaney-Bowers model and the singlet-triplet gap estimated as $0.74 \mathrm{kcal} \mathrm{mol}^{-1}$.

Theoretical calculations show that the contorted quinoidal closed-shell singlet, DBHept-TBC-CS, is lower in energy (Table S2, $\mathrm{ESI} \dagger$ ) than the triplet state in the same contorted butterfly-like or the orthogonal geometries by $>45$ or $10 \mathrm{kcal} \mathrm{mol}^{-1}$, respectively, being therefore, thermally inaccessible from DBHept-TBC-CS. Indeed, reduction of orthogonal [DBHept-TBC] $]^{2+}$ must lead to diradical in orthogonal geometry that is kinetically prevented by the steric bulk of the end-groups to convert to the more stable DBHept-TBC-CS for which we got no spectroscopic evidence. This agrees well with the rotation barrier $\left(22.7 \mathrm{kcal} \mathrm{mol}^{-1}\right)$ observed $^{13}$ for such transformation with smaller (diphenyl)methyl end-groups or the calculations $\left(20 \mathrm{kcal} \mathrm{mol}^{-1}\right)$ for model DBHept-Anthracene radical (ESI, $\dagger$ Section S7.4). ${ }^{18 e}$ Model studies suggest this stabilization is mostly kinetic unlike in case of fluorenyl end-groups ${ }^{13}$ where the orthogonal diradical is the thermodynamic product (ESI, $\dagger$ Section S7.5). This shows that the shapes of the end-groups govern the properties of diradical Chichibabin PAHs. ESR experiments, however, suggest that the DBHept-TBC ground state is singlet. Broken-symmetry DFT shows that the triplet and SOS are nearly isoergic, as expected for a diradical with fully disjoint degenerate frontier MOs (FMOs, see ESI $\dagger$ ). In this case, two mechanisms may lead to preferential stabilization of the SOS state in the orthogonal DBHept-TBC: (i) vibronic coupling or (ii) dynamic spin polarization (DSP). Vibronic coupling was suggested to affect singlet states and their reactivity in diradicals. ${ }^{22} \mathrm{CAS}(2,2)$ calculations do not show any admixture of excited states that might arise by lowering the $D_{2 \mathrm{~d}}$ symmetry of the triplet DBHept-TBC and stabilize the OS singlet. Note, however, that the dynamic electron correlation missing in CASSCF calculations and solvation could provide a different result. Therefore, DSP, the reason why diradicals with disjoint degenerate FMOs possess the singlet ground state, ${ }^{23}$ stabilizes the OS singlet, while it is absent in triplet DBHept-TBC. DBHept-TBC in orthogonal geometry is thus predicted to have a singlet OS ground state as observed in the ESR and the magnetic susceptibility experiments or by broadening of the NMR resonances. Although we can not discard formation of diamagnetic oligomers at r.t., ${ }^{24}$ clearly, paramagnetic triplet DBHept-TBC is reached upon heating. Therefore, DBHept-TBC incorporating heptagonal carbocycles is the first TBC diradical with major kinetic stabilization embedded by these end-groups.

In summary, we revealed the great impact that heptagonal carbocycles as end-groups have on the ground state in Thiele 
and Chichibabin diradical PAHs. The saddle-shaped structure imposed by distorted DBHept moieties led to a CS quinoidal geometry in DBHept-Th, while the size of planar DBHept enhanced the steric clash with central anthracenes in DBHept-TBC and kinetically stabilized the orthogonal diradical structure allowing to thermally reach the triplet diradical configuration.

The authors are grateful for the financial support from: MICIU/FEDER/AEI, Spain (PG2018-101181-B-I00, PGC2018-095808B-I00, MAT2016-80826-R, FIP-2018-HECTIC-PTM, Prometeo2019/076 and the "Severo Ochoa" Programme for Centres of Excellence in R\&D; SEV-2015-0496), the European Research Council (ERC) (677023), DGR (Catalunya) (2017-SGR-918), and SNSF (Switzerland, TŚ, PZ00P2_174175). We thank the CSIRC-Alhambra and SciCore (Basel, Switzerland) for supercomputing facilities and the Servei de $\mathrm{RMN}, \mathrm{UAB}$, for instrument time.

\section{Conflicts of interest}

There are no conflicts to declare.

\section{Notes and references}

1 (a) J. Wu, W. Pisula and K. Müllen, Chem. Rev., 2007, 107, 718-747; (b) A. Narita, X. Y. Wang, X. Feng and K. Müllen, Chem. Soc. Rev., 2015, 44, 6616-6643.

2 M. Abe, Chem. Rev., 2013, 113, 7011-7088.

3 K. Kamada, K. Ohta, T. Kubo, A. Shimizu, Y. Morita, K. Nakasuji, R. Kishi, S. Ohta, S. I. Furukawa, H. Takahashi and M. Nakano, Angew. Chem., Int. Ed., 2007, 46, 3544-3546.

4 K. M. Felter and F. C. Grozema, J. Phys. Chem. Lett., 2019, 10, 7208-7214.

5 (a) P. Mayorga-Burrezo, V. G. Jiménez, D. Blasi, I. Ratera, A. G. Campaña and J. Veciana, Angew. Chem., Int. Ed., 2019, 58, 16282-16288; (b) Q. Jin, S. Chen, Y. Sang, H. Guo, S. Dong, J. Han, W. Chen, X. Yang, F. Li and P. Duan, Chem. Commun., 2019, 55, 6583-6586; (c) P. Mayorga-Burrezo, V. G. Jiménez, D. Blasi, T. Parella, I. Ratera, A. G. Campaña and J. Veciana, Chem. - Eur. J., 2020, 26, 3776-3781.

6 M. Chikamatsu, T. Mikami, J. Chisaka, Y. Yoshida, R. Azumi, K. Yase, A. Shimizu, T. Kubo, Y. Morita and K. Nakasuji, Appl. Phys. Lett., 2007, 91, 043506.

7 (a) A. Shimizu and Y. Tobe, Angew. Chem., Int. Ed., 2011, 50, 6906-6910; (b) Z. Sun, Z. Zeng and J. Wu, Acc. Chem. Res., 2014, 47, 2582-2591.

8 (a) C. K. Frederickson, B. D. Rose and M. M. Haley, Acc. Chem. Res., 2017, 50, 977-987; (b) Y. Li, W. K. Heng, B. S. Lee, N. Aratani, J. L. Zafra, N. Bao, R. Lee, Y. M. Sung, Z. Sun, K. W. Huang, R. D. Webster, J. T. López Navarrete, D. Kim, A. Osuka, J. Casado, J. Ding and J. Wu, J. Am. Chem. Soc., 2012, 134, 14913-14922; (c) A. Konishi, Y. Hirao, M. Nakano, A. Shimizu, E. Botek, B. Champagne, D. Shiomi, K. Sato, T. Takui, K. Matsumoto, H. Kurata and T. Kubo, J. Am. Chem. Soc., 2010, 132, 11021-11023; (d) P. Ravat, T. Šolomek, M. Rickhaus, D. Häussinger, M. Neuburger, M. Baumgarten and M. Juríček, Angew. Chem., Int. Ed., 2016, 55, 1183-1186.

9 J. Thiele and H. Balhorn, Chem. Ber., 1904, 37, 1463-1470.

10 E. Tschitschibabin, Chem. Ber., 1907, 40, 1810-1819.
11 T. Y. Gopalakrishna, W. Zeng, X. Lu and J. Wu, Chem. Commun., 2018, 54, 2186-2199.

12 Z. He, L. Shan, J. Mei, H. Wang, J. W. Y. Lam, H. H. Y. Sung, I. D. Williams, X. Gu, Q. Miao and B. Z. Tang, Chem. Sci., 2015, 6, 3538-3543.

13 (a) Z. Zeng, Y. M. Sung, N. Bao, D. Tan, R. Lee, J. L. Zafra, B. S. Lee, M. Ishida, J. Ding, J. T. López Navarrete, Y. Li, W. Zeng, D. Kim, K.-W. Huang, R. D. Webster, J. Casado and J. Wu, J. Am. Chem. Soc., 2012, 134, 14513-14525; (b) Z. Lim, B. Zheng, K. W. Huang, Y. Liu and J. Wu, Chem. - Eur. J., 2015, 21, 18724-18729.

14 (a) T. Nishiuchi, R. Ito, E. Stratmann and T. Kubo, J. Org. Chem., 2020, 85, 179-186; (b) Y. Ishigaki, T. Hashimoto, K. Sugawara, S. Suzuki and T. Suzuki, Angew. Chem., Int. Ed., 2020, 59, 6581-6584. Some examples on singlet carbenes as end-groups, see: (c) D. Rottschäfer, B. Neumann, H. Stammler, D. M. Andrada and R. S. Ghadwal, Chem. Sci., 2018, 9, 4970-4976; (d) D. Rottschäfer, N. K. T. Ho, B. Neumann, H. Stammler, M. Gastel, D. M. Andrada and R. S. Ghadwal, Angew. Chem., Int. Ed., 2018, 57, 5838-5842; (e) D. Rottschäfer, J. Busch, B. Neumann, H. Stammler, M. Gastel, R. Kishi, M. Nakano and R. S. Ghadwal, Chem. - Eur. J., 2018, 24, 16537-16542; $(f)$ J. Messelberger, A. Grünwald, P. Pinter, M. M. Hansmann and D. Munz, Chem. Sci., 2018, 9, 6107-6117; $(g)$ G. Kundu, S. De, S. Tothadi, A. Das, D. Koley and S. S. Sen, Chem. - Eur. J., 2019, 25, 16533-16537; (h) A. Maiti, J. Stubbe, N. I. Neuman, P. Kalita, P. Duari, C. Schulzke, V. Chandrasekhar, B. Sarkar and A. Jana, Angew. Chem., Int. Ed., 2020, 59, 6729-6734.

15 X. Yin, J. Z. Low, K. J. Fallon, D. W. Paley and L. M. Campos, Chem. Sci., 2019, 10, 10733-10739.

16 Y. Ishigaki, Y. Hayashi and T. Suzuki, J. Am. Chem. Soc., 2019, 141, 18293-18300.

17 V. G. Jiménez, R. Tapia, M. A. Medel, I. F. A. Mariz, T. Ribeiro, V. Blanco, J. M. Cuerva, E. Maçôas and A. G. Campaña, Chem. Commun., 2018, 54, 3359-3362.

18 (a) M. P. Cava and R. H. Schlessinger, J. Am. Chem. Soc., 1963, 85, 835-836; (b) J. Kolc and J. Michl, J. Am. Chem. Soc., 1973, 95, 7391-7401; (c) J. Liu, S. Mishra, C. A. Pignedoli, D. Passerone, J. I. Urgel, A. Fabrizio, T. G. Lohr, J. Ma, H. Komber, M. Baumgarten, C. Corminboeuf, R. Berger, P. Ruffieux, K. Müllen, R. Fasel and X. Feng, J. Am. Chem. Soc., 2019, 141, 12011-12020; (d) A. Konishi, K. Horii, D. Shiomi, K. Sato, T. Takui and M. Yasuda, J. Am. Chem. Soc., 2019, 141, 10165-10170; (e) T. Nishiuchi, R. Ito, A. Takada, Y. Yasuda, T. Nagata, E. Stratmann and T. Kubo, Chem. - Asian J., 2019, 14, 1830-1836; $(f)$ X. Fu, H. Han, D. Zhang, H. Yu, Q. Ho and D. Zhao, Chem. Sci., 2020, 11, 5565-5571.

19 (a) G. Wittig, E. Dreher, W. G. Wittig, E. Dreher, W. Reuther, H. Weidinger and R. Steinmetz, Justus Liebigs Ann. Chem., 1969, 726, 188-200; (b) J. Ipaktschi, R. Hosseinzadeh and P. Schlaf, Angew. Chem., Int. Ed., 1999, 38, 1658-1660; (c) D. Beaudoin, O. LevasseurGrenon, T. Maris and J. D. Wuest, Angew. Chem., Int. Ed., 2016, 55, 894-898.

20 Y. Sakano, R. Katoono, K. Fujiwara and T. Suzuki, Chem. Lett., 2014, 43, 1143-1145.

21 (a) T. Kubo, A. Shimizu, M. Sakamoto, M. Uruichi, K. Yakushi, M. Nakano, D. Shiomi, K. Sato, T. Takui, Y. Morita and K. Nakasuji, Angew. Chem., Int. Ed., 2005, 44, 6564-6568; (b) C. Wentrup, M. J. Regimbald-Krnel, D. Müller and P. Comba, Angew. Chem., Int. Ed., 2016, 55, 14600-14605.

22 T. Šolomek, P. Ravat, Z. Mou, M. Kertesz and M. Juríček, J. Org. Chem., 2018, 83, 4769-4774.

23 (a) P. G. Wenthold, D. A. Hrovat, W. T. Borden and W. C. Lineberger, Science, 1996, 272, 1456-1459; (b) W. C. Lineberger and W. T. Borden, Phys. Chem. Chem. Phys., 2011, 13, 11792-11813.

24 Q. Xiang, J. Guo, J. Xu, S. Ding, Z. Li, G. Li, H. Phan, Y. Gu, Y. Dang, Z. Xu, Z. Gong, W. Hu, Z. Zeng, J. Wu and Z. Sun, J. Am. Chem. Soc., 2020, 142, 11022-11031. 